\title{
BMJ Open Burn injury, gender and cancer risk: population-based cohort study using data from Scotland and Western Australia
}

\author{
Janine M Duke, ${ }^{1}$ Jacqui Bauer, ${ }^{2}$ Mark W Fear, ${ }^{1}$ Suzanne Rea, ${ }^{1,3}$ \\ Fiona M Wood, ${ }^{1,3,4}$ James Boyd ${ }^{2}$
}

To cite: Duke JM, Bauer J, Fear MW, et al. Burn injury, gender and cancer risk: population-based cohort study using data from Scotland and Western Australia. BMJ Open 2014;4: e003845. doi:10.1136/ bmjopen-2013-003845

- Prepublication history for this paper is available online. To view these files please visit the journal online (http://dx.doi.org/10.1136/ bmjopen-2013-003845).

Received 19 August 2013 Accepted 19 December 2013

CrossMark

For numbered affiliations see end of article.

Correspondence to Professor Janine M Duke; janine.duke@uwa.edu.au

\begin{abstract}
Objective: To investigate the risk of cancer and potential gender effects in persons hospitalised with burn injury.

Design: Population-based retrospective cohort study using record-linkage systems in Scotland and Western Australia.

Participants: Records of 37890 and 23450 persons admitted with a burn injury in Scotland and Western Australia, respectively, from 1983 to 2008. Deidentified extraction of all linked hospital morbidity records, mortality and cancer records were provided by the Information Service Division Scotland and the Western Australian Data Linkage Service.
\end{abstract}

Main outcome measures: Total and gender-specific number of observed and expected cases of total ('all sites') and site-specific cancers and standardised incidence ratios (SIRs).

Results: From 1983 to 2008, for female burn survivors, there was a greater number of observed versus expected notifications of total cancer with 1011 (SIR, 95\% Cl 1.3, 1.2 to 1.4 ) and 244 (SIR, 95\% Cl 1.12, 1.05 to 1.30), respectively, for Scotland and Western Australia. No statistically significant difference in total cancer risk was found for males. Significant excesses in observed cancers among burn survivors (combined gender) in Scotland and Western Australian were found for buccal cavity, liver, larynx and respiratory tract and for cancers of the female genital tract.

Conclusions: Results from the Scotland data confirmed the increased risk of total ('all sites') cancer previously observed among female burn survivors in Western Australia. The gender dimorphism observed in this study may be related to the role of gender in the immune response to burn injury. More research is required to understand the underlying mechanism(s) that may link burn injury with an increased risk of some cancers.

\section{INTRODUCTION}

The burden of burn injury is a significant issue, not only in terms of the acute care perspective but also the chronic health effects resulting from the injury event and the subsequent treatments. While burns predominantly

\section{Strengths and limitations of this study}

Population-level linked administrative data minimise the issues of selection and reporting bias, and loss to follow-up.

- Consistency of results using population-level data from two patient populations provides a greater support for link between burn injury and some cancers.

- Unable to examine the impact of burn severity on cancer risk due to lack of available data.

affect the skin, burns are associated with significant systemic effects, ${ }^{1-3}$ depressed immune functioning ${ }^{4-8}$ and prolonged periods of systemic catabolism and hypermetabolism. Prompted by a clinical scenario of a diagnosis of hepatocellular carcinoma in a young male burn patient, ${ }^{10}$ and the potential for malignancy after burn, an initial study of burn injury and total (all sites) cancer risk was undertaken. ${ }^{11}$

Results of our initial study demonstrated a gender effect with female burn survivors having an increased risk of all types of cancer. ${ }^{11}$ In contrast to our results, a Swedish population-based study ${ }^{12}$ that linked burn patient hospitalisation records and cancer registrations reported the risk of developing any form of cancer for combined gender was increased (standardised incidence ratio (SIR), 95\% CI 1.11, 1.06 to 1.16), with the risk of lung cancer also significantly increased (SIR, 95\% CI 1.39, 1.21 to 1.59 ). However, a Danish study of burn patients ${ }^{13}$ found no significant increases in cancer (combined gender) for all malignant neoplasms, including all skin cancers (SIR, 95\% CI $0.99,0.93$ to 1.06 ).

This previous study of burn injury and cancer risk used population-based data linked by the Western Australian Data 
Linkage System (WADLS). ${ }^{14}$ Western Australia has a population of approximately 2.2 million, and as such, did not support detailed gender-specific and site-specific cancer incidence assessments with adequate statistical power. While the WADLS has linked datasets of Western Australians since the 1970s, other Australian states have only recently established record linkage systems and were not able to support this study. To extend the population base and enable further detailed examination of the observed gender effect and site-specific cancer incidence, approval was sought to access the Scottish population-based record linkage system, the Information Service Division (ISD) Scotland, ${ }^{15}$ that has routinely linked health data since the 1980s.

This article reports a retrospective longitudinal study to explore cancer risk after burn injury using linked hospital morbidity, cancer and death data of persons hospitalised for burn injury in Western Australia and Scotland. The study aimed to, first, confirm the increased risk of total ('all sites') cancer observed in the preliminary Western Australian study of female burn survivors using the Scottish data; and, second, examine sitespecific cancer risk among survivors of burn injury.

\section{METHODS}

Study data were obtained from the WADLS ${ }^{14}$ and the ISD (Scotland) of the National Health Service (NHS) National Services Scotland ${ }^{15}$. The WADLS and ISD Scotland are validated record linkage systems that routinely link administrative health data from core datasets for the entire population of Western Australia and Scotland, respectively.

An index burn injury was defined as the first hospital admission with a burn injury using primary and additional diagnosis International Classification of Diseases (ICD) codes 940-949 (ICD9) and T20-T31 (ICD10). A deidentified extraction of all linked hospital morbidity records (Hospital Morbidity Data System (HMDS), mortality (Death Register, Western Australia) and cancer records (Western Australia Cancer Registry (WACR)) for all persons admitted to hospital with an index burn injury in Western Australia, for the period 1 January 1983 to 31 December 2008, was performed by WADLS. ${ }^{16}$ A corresponding deidentified extraction of all linked hospital morbidity records (Scottish Morbidity Records (SMR) 01), cancer registrations (SMR06) and death records (General Register Office for Scotland (GROS)) using the same burn cohort definition was undertaken by ISD Scotland. Hospital admissions data items included age at admission, gender, admission date, separation (or discharge) date, principal and additional diagnoses and external cause of injury.

The WACR was established in 1981 and is a population-based cancer registry based on mandatory notification of cancers from pathologists, haematologists and radiation oncologist, and cancer information from death records. ${ }^{17}$ Malignant cancers are coded according to a modified Australian version of the International Classification of Diseases, Tenth Revision (ICD10-AM) and International Classification of Diseases for Oncology (ICD-O-3).

The Scotland Cancer Registry (SMR06) has recorded all incident cancers in Scotland from 1958, and since 1997 registration has been centralised at ISD Scotland. ${ }^{18}$ The registry is responsible for the collection of information on all new cases of primary malignant neoplasms, carcinoma in situ (including grade III intraepithelial neoplasia), neoplasms of uncertain behaviour and (since 1 January 2000) benign brain and spinal cord tumours arising in residents of Scotland. Data quality is monitored using routine indicators, computer validation and ad hoc studies of data accuracy and completeness of ascertainment. ${ }^{19} 20$ The Scottish cancer notifications are coded using the ICD V.10 and the ICD-O.

Methods for analysis have been previously published. ${ }^{11}$ An incident cancer was defined as a cancer diagnosis notification (C00-C96, excluding C44) after hospital admission for index burn injury. Analysis was restricted to malignant neoplasm notifications (C00-C96, excluding C44) for which total (all sites) and site-specific cancer incident rates were provided by WACR and ISD Scotland for respective populations. Records were excluded from the analysis if the date of cancer diagnosis was prior to date of discharge for index burn hospitalisation. When a record was identified as having more than one malignant neoplasm notification, each neoplasm was counted as an individual record; however, if multiple tumours of the skin (C43) with identical morphological characteristics (ie, the first three digits ICD-O-3 morphology code) were identified, they were recorded only once. Gender and age-specific cancer (total C00-C96, excluding C44) incident rates for the Western Australian and Scottish populations were pooled for the calendar periods 1983-1988, 1989-1993, 1994-1998, 1999-2003 and 2004-2008 to allow for changes in population cancer incidence during the study period.

For the determination of incident rates, the calculation of person-years began on the day of final hospital discharge for the index burn admission, and the study observation period continued until date of the defined cancer diagnosis, death or 31 December 2008, whichever occurred first. Individual calculations were conducted for total (all sites) and site-specific cancers. The observed number of cases of cancer and person-years at risk were calculated by age (5-year age groups), gender and calendar period (1983-1988, 1989-1993, 19941998, 1999-2003 and 2004-2008). The expected number of cancer cases was estimated by multiplying the specific number of person-years per category by the corresponding incidence of cancer in Western Australia, Scotland, and combined cancer incidence rates, provided by WACR and ISD Scotland. SIRs were calculated by dividing the observed number of cases by the number expected. ${ }^{21} 22$ The $95 \%$ CIs were defined under 
the assumption that the observed number of cancers followed the Poisson distribution. ${ }^{23}$

Separate SIR analyses for total (all sites) and sitespecific cancers were conducted using country-specific data for respective burn patient cohorts (all burn depth) hospitalised from 1983 to 2008; total (all sites) SIRs were repeated for subcohorts of burn admissions from 1983 to 1987 , with an optimum follow-up time. To further explore the gender impact of burn injury on cancer risk, total (all sites) cancer SIR analyses were repeated on age-restricted subcohorts classified to reflect the reproductive age at admission for burn injury: $<15$; $15-$ 49 and $\geq 50$ years. All statistical analyses were performed using Stata statistical software V.11 (StataCorp LP, College Station, Texas, USA).

\section{RESULTS}

As previously reported, in Western Australia from 1983 to 2008, there were 23450 hospital index admissions for burnrelated injury. ${ }^{16}$ After exclusion of records with a history of cancer prior to separation date or death during hospital admission for burn, a total of 22705 patient records were included in the analysis. ${ }^{11}$ There were 673 patients with a first cancer notification after the date of separation for burn injury hospitalisation, and with inclusion of multiple malignancies, 759 cancer notifications were included in the SIR analyses as independent observations.

In Scotland from 1983 to 2008, there were a total of 37890 persons hospitalised for an index burn-related injury. After exclusion of those with a history of cancer prior to separation date or death during hospital admission for burn, a total of 37506 patients were included in the analysis. There were 2005 patients with a first cancer notification after the date of separation for burn injury hospitalisation, and with inclusion of multiple malignancies, 2260 cancer notifications were included in the SIR analyses as independent observations. The characteristics of the Western Australia and Scotland cohorts are presented in table 1 .

The Western Australia cohort (1983-2008; combined gender) was followed for a total of 283306 person-years, with a mean follow-up time of 12.3 years (range $>0-25.9$ years). The mean follow-up time for those with a cancer notification was 9.4 years (range $>0-25.4$ years) and for those with no cancer notification was 12.4 years (range $>0-25.9$ years). The Scotland cohort (1983-2008; combined gender) was followed for a total of 474489 person-years, with a mean follow-up time of 12.6 years (range $0-26.0$ years). The mean follow-up time for those with a cancer notification was 9.4 years (range $>0-25.8$ years) and for those with no cancer notification was 12.7 years (range $>0-26$ years).

For the Scottish cohort of burn-injury patients (combined gender), there was a marginal but significant difference (SIR, 95\% CI 1.09, 1.05 to 1.10 ) in the overall risk of cancer for persons with a burn injury hospitalisation for the period 1983-2008, compared with the general population of Scotland. While a significant
Table 1 Characteristics of burn injury patients included in analyses with no record of cancer prior to separation date of index burn admission, 1983-2008, by country

\begin{tabular}{|c|c|c|}
\hline Characteristics & $\begin{array}{l}\text { Western } \\
\text { Australia } \\
\mathrm{N}(\%)\end{array}$ & $\begin{array}{l}\text { Scotland } \\
\text { N (\%) }\end{array}$ \\
\hline $\begin{array}{l}\text { Total number burn } \\
\text { admissions* }\end{array}$ & 22705 & 3537506 \\
\hline Gender: male & $15481(68.2)$ & $23896(63.7)$ \\
\hline \multicolumn{3}{|c|}{ Age at index admission (years) } \\
\hline$<15$ & $8135(35.8)$ & $14579(38.9)$ \\
\hline $15-24$ & 4364 (19.2) & 4495 (12.0) \\
\hline $25-49$ & $7147(31.5)$ & $9554(25.5)$ \\
\hline $50-64$ & $1736(7.7)$ & $4080(10.9)$ \\
\hline $65+$ & $1323(5.8)$ & 4798 (12.8) \\
\hline \multicolumn{3}{|l|}{ Site of burnt } \\
\hline Head and neck & $6784(15.4)$ & $7592(16.1)$ \\
\hline Trunk & $7553(17.2)$ & $8815(21.0)$ \\
\hline Hand, wrist, upper & 15801 (35.9) & $6984(14.8)$ \\
\hline \multicolumn{3}{|l|}{ limb } \\
\hline Hip, lower limb & $11798(26.8)$ & $9531(3.4)$ \\
\hline Eye & $379(0.9)$ & $1087(2.3)$ \\
\hline Respiratory tract & $212(0.5)$ & $163(0.3)$ \\
\hline Other internal organs & $124(0.3)$ & $165(0.3)$ \\
\hline Multiple regions & $656(1.5)$ & $3677(7.8)$ \\
\hline Unspecified region & $694(1.6)$ & $858(1.8)$ \\
\hline \multicolumn{3}{|l|}{ Burn site depth† } \\
\hline Erythema & $8929(20.9)$ & $4815(11.5)$ \\
\hline Partial thickness & 18449 (41.9) & $6302(15.0)$ \\
\hline Full thickness & $7095(16.1)$ & $4924(11.7)$ \\
\hline Unspecified & $9528(21.7)$ & $25869(61.7)$ \\
\hline \multicolumn{3}{|c|}{ Calendar period of admission } \\
\hline 1983-1988 & $5431(23.9)$ & $11507(30.7)$ \\
\hline $1989-1993$ & $4200(18.5)$ & $7876(21.0)$ \\
\hline 1994-1998 & $4755(20.9)$ & $7130(19.0)$ \\
\hline 1999-2003 & 4265 (18.9) & $5980(15.9)$ \\
\hline 2004-2008 & 4054 (17.9) & $5013(13.4)$ \\
\hline \multicolumn{3}{|c|}{ Any comorbidity at index burn } \\
\hline Yes & 2798 (12.3) & 7679 (20.5) \\
\hline
\end{tabular}

${ }^{*}$ No previous record of cancer.

†Patients may have multiple burn sites per anatomical region per depth.

increase of $30 \%$ in cancer risk was estimated for females, there was no difference in cancer risk for males, when compared with the general population of Scotland (refer to table 2). For the subcohort of burn injury patients hospitalised during 1983-1988, the total observed number of cases of cancer $(\mathrm{n}=838)$ was statistically significantly lower than expected $(\mathrm{n}=953.4)$ with SIR $(95 \% \mathrm{CI})$ of 0.88 (0.82 to 0.94$)$, with males having a statistically significantly lower number of cases observed than expected. Refer to table 2 for gender-specific SIRs for total (all sites) cancer for Scotland and Western Australian burn patients, hospitalised during 1983-1988 and $1983-2008 .^{11}$

Female genital cancers were grouped due to the small number of observed cancers in subgroups in the Western Australian data and unstable SIR results. Statistically 
Table 2 SIRs and 95\% Cls and observed and expected number for total (all sites) cancer in persons hospitalised for burn injury in Western Australia and Scotland, during the periods 1983-2008 and 1983-1988

\begin{tabular}{|c|c|c|c|c|c|c|}
\hline & \multicolumn{3}{|c|}{ Western Australia* } & \multicolumn{3}{|l|}{ Scotland } \\
\hline & $\begin{array}{l}\text { Combined } \\
\text { SIR 95\% Cl¥ } \\
\text { 0:E }\end{array}$ & $\begin{array}{l}\text { Male† } \\
\text { SIR 95\% CI } \\
\text { O:E }\end{array}$ & $\begin{array}{l}\text { Female† } \\
\text { SIR } 95 \% \mathrm{CI} \\
\text { O:E }\end{array}$ & $\begin{array}{l}\text { Combined } \\
\text { SIR } 95 \% \mathrm{CI} \\
\text { O:E }\end{array}$ & $\begin{array}{l}\text { Male† } \\
\text { SIR } 95 \% \mathrm{CI} \\
\text { O:E }\end{array}$ & $\begin{array}{l}\text { Female† } \\
\text { SIR } 95 \% \mathrm{CI} \\
\text { O:E }\end{array}$ \\
\hline Total cohort & 0.97 (0.9 to 1.0$)$ & 0.9 (0.8 to 1.0$)$ & 1.1 (1.0 to 1.3$)$ & 1.09 (1.05 to 1.10$)$ & $0.96(0.90$ to 1.0$)$ & $1.3(1.2$ to 1.4$)$ \\
\hline 1983-2008 & 759: 785.5 & 515: 569.5 & 244: 216.0 & 2260: 2075.9 & 1249: 1303.2 & 1011: 772.6 \\
\hline Subcohort & $1.0(0.9$ to 1.1$)$ & 0.9 (0.8 to 1.0$)$ & $1.4(1.1$ to 1.7$)$ & 0.9 (0.8 to 0.9$)$ & 0.8 (0.7 to 0.9$)$ & 1.0 (0.9 to 1.2$)$ \\
\hline 1983-1988 & $294: 294.9$ & $190: 220.3$ & 104: 74.6 & 838: 953.4 & $491: 614.3$ & 347: 339.1 \\
\hline
\end{tabular}

significant increases in observed genital (combined) cancers for female burn patients in Western Australia and Scotland were found. The increased breast cancer incidence was statistically significant among female burn survivors in Scotland. Statistically significant increases in cancer incidence for combined gender for Western Australia and Scottish data were observed for cancers of the buccal cavity, liver and respiratory tract. Refer to table 3 for gender-specific and site-specific cancer SIRs. For each of these cancers, female burn survivors in Western Australia and Scotland had a higher incidence than males when compared with respective general population data. For the majority of site-specific cancers selected, female burn survivors in Western Australia and Scotland had a higher number of observed cancers than expected, with SIRs of similar magnitude. However, SIR results for Scottish data reached statistical significance, reflecting the larger population base and respective higher number of cancer notifications.

Table 4 presents an SIR analyses of total (all sites) cancer risk repeated on age-restricted subcohorts, classified to reflect the reproductive age $(<15 ; 15-49$ and $\geq 50$ years) at admission for burn injury. For males in both WA and Scotland, no statistically significant differences were found across the three age groups. For female burn survivors in Scotland, the observed number of total cancer (all sites) exceeded that expected for each of the three age groups, with statistically significant results observed for the age groups 15-49 and for those aged 50 years and older. In the Western Australia data, excess cancers were observed for those younger than 15 years and for those 50 years and older, with statistical significance reached for the older age group; for females aged 15-49 years at burn injury, no difference in observed and expected total (all sites) cancer was found.

\section{DISCUSSION}

\section{Methodological issues}

When population-level administrative data are used, data linkage minimises issues of selection and reporting bias, as well as loss to follow-up. Data quality of the Western
Australia and Scottish Cancer Registers ${ }^{17} 1920$ and hospital morbidity datasets ${ }^{24}$ are assessed continually for accuracy and quality. Data of all index burn hospitalisations in Western Australia and Scotland from 1983 to 2008 were analysed with a follow-up time from discharge date, allowing for exclusion of prevalent cancers to support temporality of burn exposure and incident cancer. Cancer diagnoses from cancer registries in Western Australia and Scotland were independent of the record of burn injury in the respective hospital morbidity datasets. Minor burns treated in emergency departments were not included in the study. The burn patient cohorts under study are part of the respective reference populations, and as such, this may have a small diluting effect in the SIRs. Using parallel datasets from Western Australia and Scotland, with 2.2 million and 5.5 million populations, respectively, allowed examination of the consistency of results and trends across the populations.

The Western Australia hospital morbidity data records the principal diagnosis and up to 20 additional diagnosis fields, whereas the Scottish morbidity data include the principal diagnosis and five additional diagnosis fields. Consequent to the reduced number of additional diagnosis fields in the Scottish data, there was an absence of recorded supplementary total body surface area burned (TBSA\%) data (ICD9 946; ICD10 T31) and a greater use of ICD codes for burns to multiple regions of the body (ICD9 946; ICD10 T29) rather than to individual anatomic burn sites, as reflected in table 1. This limited SIR analyses restricted to more severe burns of TBSA $20 \%$ or greater and incident rate ratio analysis to examine the effects of severity of burn injury (burn depth and TBSA $\%)$. Previous SIR analyses of total (all sites) cancer risk in Western Australia showed similar trends in results for all burn patients (severe and non-severe). ${ }^{11}$

Although this study had a follow-up period of up to 26 years from the date of separation for admission for burn injury, the follow-up period for many patients may not have provided sufficient observation time to enable identification of all potential malignancies, given the long latency period for many cancers. Further burn injury research is planned with comparison cohorts (non-burn trauma, no injury), using incidence rate ratio 
Table 3 SIRs and 95\% Cls and observed and expected numbers for selected types of cancer in persons hospitalised for burns in Western Australia and Scotland, 1983-2008

\begin{tabular}{|c|c|c|c|c|c|c|}
\hline \multirow[b]{2}{*}{ Cancer Site ICD-10* } & \multicolumn{3}{|c|}{ Western Australia } & \multicolumn{3}{|l|}{ Scotland } \\
\hline & $\begin{array}{l}\text { Combined } \\
\text { SIR 95\% Cl† } \\
\text { O:E }\end{array}$ & $\begin{array}{l}\text { Male } \\
\text { SIR 95\% Cl¥ } \\
\text { O:E }\end{array}$ & $\begin{array}{l}\text { Female } \\
\text { SIR 95\% Cl¥ } \\
\text { O:E }\end{array}$ & $\begin{array}{l}\text { Combined } \\
\text { SIR 95\% Cl¥ } \\
\text { O:E }\end{array}$ & $\begin{array}{l}\text { Male } \\
\text { SIR 95\% Cl¥ } \\
\text { O:E }\end{array}$ & $\begin{array}{l}\text { Female } \\
\text { SIR 95\% Cl¥ } \\
\text { O:E }\end{array}$ \\
\hline Buccal cavity & $1.4(1.03$ to 1.9$)$ & $1.4(1.0$ to 1.9$)$ & 1.5 (0.7 to 3.2$)$ & 2.6 (2.2 to 3.1$)$ & 2.4 (1.9 to 2.9 ) & 3.4 (2.5 to 4.8$)$ \\
\hline $\mathrm{C} 00$ to $\mathrm{C} 14$ & 45: 32.6 & $38: 28.1$ & $7: 4.6$ & $117: 45.0$ & 83: 35.1 & $34: 9.9$ \\
\hline Oesophagus & 1.4 (0.9 to 2.4$)$ & 1.5 (0.9 to 2.6$)$ & (0.3 to 4.5$)$ & 1.6 (1.3 to 2.0$)$ & 1.5 (1.1 to 1.9$)$ & 1.9 (1.3 to 2.7$)$ \\
\hline C15 & $15: 10.50$ & 13: 8.7 & $2: 1.8$ & 82: 51.4 & $53: 36.1$ & $29: 15.3$ \\
\hline Stomach & 0.6 (0.3 to 1.1$)$ & $0.5(0.2$ to 1.1$)$ & 0.8 (0.3 to 2.6$)$ & $1.2(0.9$ to 1.5$)$ & (0.8 to 1.5$)$ & (0.9 to 1.9$)$ \\
\hline C16 & $10: 17.0$ & $7: 13.4$ & 3: 3.6 & $73: 63.2$ & $5: 2.8$ & $25: 19.5$ \\
\hline Colorectal & 0.7 (0.6 to 0.9$)$ & 0.7 (0.5 to 0.9$)$ & 0.9 (0.6 to 1.3$)$ & $1.2(1.1$ to 1.4$)$ & (0.9 to 1.2$)$ & (1.3 to 1.8$)$ \\
\hline $\mathrm{C} 18$ to $\mathrm{C} 20$ & 69: 96.3 & 45: 69.1 & 24: 27.2 & $268: 221.8$ & $142: 140.5$ & 125: 81.3 \\
\hline Liver & 2.6 (1.6 to 4.0$)$ & 2.2 (1.3 to 3.7$)$ & 4.7 (2.0 to 11.4$)$ & 1.7 (1.2 to 2.5$)$ & (1.1 to 2.5$)$ & 1.9 (1.0 to 3.7$)$ \\
\hline C22 & 19: 7.4 & $14: 6.3$ & $5: 1.1$ & $31: 18.0$ & 22: 13.3 & $9: 4.7$ \\
\hline Pancreas & 0.7 (0.4 to 1.3$)$ & $0.9(0.5$ to 1.7$)$ & $0.4(0.1$ to 1.6$)$ & $1.1(0.8$ to 1.5$)$ & 1.5 (1.03 to 2.0$)$ & 0.6 (0.3 to 1.2$)$ \\
\hline C25 & $11: 15.3$ & 9: 10.4 & 2: 5.0 & $44: 39.6$ & $34: 23.4$ & 10: 16.2 \\
\hline Larynx & 5.7 (0.9 to 3.3 ) & 1.5 (0.7 to 3.0$)$ & 6.0 (1.5 to 24.1$)$ & 1.9 (1.4 to 2.5$)$ & 1.5 (1.1 to 2.2 )" & $4.2(2.3$ to 7.7$)$ \\
\hline C32 & $10: 5.7$ & $8: 5.4$ & $2: 0.3$ & 39: 21.1 & 28: 18.5 & $11: 2.6$ \\
\hline Respiratory tract & $1.4(1.1$ to 1.6$)$ & $1.3(1.1$ to 1.7$)$ & 1.4 (0.9 to 2.2$)$ & 1.5 (1.4 to 1.7$)$ & $1.3(1.2$ to 1.5$)$ & 1.9 (1.7 to 2.2$)$ \\
\hline C33 to $\mathrm{C} 34$ & 101: 74.8 & $79: 59.3$ & $22: 15.4$ & $448: 298.1$ & $279: 210.4$ & $169: 87.7$ \\
\hline Skin-malignant melanoma & 0.7 (0.6 to 0.9$)$ & $0.7(0.6$ to 1.0$)$ & $0.6(0.4$ to 1.0$)$ & 0.8 (0.6 to 1.1$) "$ & $0.7(0.4$ to 1.1$)$ & $(0.4$ to 1.1$)$ \\
\hline $\mathrm{C} 43$ & 72: 102.0 & 57: 77.9 & $15: 24.1$ & $38: 48.5$ & $19: 28.4$ & $19: 20.0$ \\
\hline Breast" & (0.8 to 1.3$)$ & $1.3(0.2$ to 9.2$)$ & $1.0(0.8$ to 1.3$)$ & $1.7(1.5$ to 1.9$)$ & $0.7(0.1$ to 4.8$)$ & (1.5 to 1.9$)$ \\
\hline C50 & 65: 62.4 & 1: 0.8 & $64: 61.7$ & $271: 161.4$ & $1: 1.5$ & 270: 160.0 \\
\hline Female genital tract (combined) & & & $1.4(1.0$ to 2.0$)$ & & & 1.7 (1.4 to 2.0$)$ \\
\hline C51 to C57 & & & $31: 26.7$ & & & $114: 67.2$ \\
\hline Male genital tract (combined) & & $0.9(0.8$ to 1.1$)$ & & & 1.1 (1.0 to 1.3$)$ & \\
\hline $\mathrm{C} 60$ to $\mathrm{C} 63$ & & 141: 150.7 & & & 210: 192.6 & \\
\hline Prostate & & 0.8 (0.6 to 0.9$)$ & & & $1.1(0.9$ to 1.2$)$ & \\
\hline C61 & & 102: 135.9 & & & $177: 165.5$ & \\
\hline \multirow[t]{2}{*}{ Kidney, Bladder, UT C64 to C68 } & 0.5 (0.3 to 0.7$) "$ & $0.4(0.2$ to 0.7$)$ & 0.7 (0.3 to 1.7$)$ & $1.2(1.0$ to 1.4$)$ & $1.2(1.0$ to 1.4$)$ & $1.4(1.0$ to 1.9$)$ \\
\hline & 17: 37.9 & 12: 30.9 & 5: 7.0 & 135: 110.9 & 96: 82.8 & 39: 28.0 \\
\hline Brain & $1.2(0.7$ to 1.9$)$ & $1.0(0.5$ to 1.8$)$ & 1.7 (0.8 to 3.9$)$ & 1.5 (1.1 to 2.0$)$ & 1.4 (0.9 to 2.0$)$ & (1.0 to 2.9$)$ \\
\hline $\mathrm{C} 71$ & 16: 13.9 & 10: 10.5 & $6: 3.5$ & $39: 27.0$ & $26: 19.2$ & $13: 7.8$ \\
\hline \multirow[t]{2}{*}{ Lymphomas to all } & (0.7 to 1.4$)$ & 0.8 (0.5 to 1.2$)$ & 1.7 (1.03 to 2.7 ) & $1.1(0.9$ to 1.4$)$ & 1.1 (0.8 to 1.4$)$ & $1.2(0.8$ to 1.7$)$ \\
\hline & 36: 35.5 & $20: 26.0$ & $16: 9.6$ & $75: 68.0$ & $48: 45.0$ & $27: 23.0$ \\
\hline \multirow[t]{2}{*}{ Myeloma/plasma } & $1.3(0.7$ to 2.3$)$ & $1.3(0.7$ to 2.6$)$ & $1.2(0.4$ to 3.7$)$ & $1.1(0.7$ to 1.6$)$ & (0.6 to 1.7$)$ & 1.2 (0.6 to 2.2 ) \\
\hline & $11: 8.6$ & $8: 6.1$ & 3: 2.49 & $22: 21.0$ & $13: 13.2$ & $9: 7.8$ \\
\hline \multirow[t]{2}{*}{ Leukaemia's to all } & $1.1(0.8$ to 1.7$)$ & $1.1(0.7$ to 1.8$)$ & $1.2(0.6$ to 2.5$)$ & $1.3(1.01$ to 1.7$)$ & (0.73 to 1.4$)$ & (1.3 to 2.7$)$ \\
\hline & 26: 22.9 & 19: 17.0 & $7: 6.0$ & $63: 48.6$ & $34: 33.1$ & 29: 15.5 \\
\hline
\end{tabular}

*ICD-10: International Classification of Diseases V.10.

†SIR (95\% Cl)adjusted for age and gender.

$\neq$ SIR $(95 \% \mathrm{Cl})$ adjusted for age $(95 \% \mathrm{Cl})$.

O:E, Observed:expected; SIR $(95 \% \mathrm{CI})$, standardised incidence ratio $(95 \% \mathrm{CI})$. 
Table 4 SIRs and 95\% Cls and observed and expected number for total (all sites) cancer incidence, for persons hospitalised for burns in Western Australia and Scotland, by age group, 1983-1988

\begin{tabular}{|c|c|c|c|}
\hline \multirow[b]{2}{*}{ Age at first burn years } & \multicolumn{3}{|l|}{$\begin{array}{l}\text { SIR }(95 \% \mathrm{CI}) \\
\text { (observed: expected) }\end{array}$} \\
\hline & Combined gender* & Male† & Female† \\
\hline \multicolumn{4}{|l|}{$<15$} \\
\hline WA & $\begin{array}{l}1.17(0.82 \text { to } 1.68) \\
(30: 25)\end{array}$ & $\begin{array}{l}1.19(0.77 \text { to } 1.84) \\
(20: 16)\end{array}$ & $\begin{array}{l}1.15(0.62 \text { to } 2.14) \\
(10: 8.6)\end{array}$ \\
\hline Scotland & $\begin{array}{l}0.94(0.69 \text { to } 1.28) \\
(41: 43.69)\end{array}$ & $\begin{array}{l}0.72(0.47 \text { to } 1.12) \\
(20: 27.77)\end{array}$ & $\begin{array}{l}1.32(0.86 \text { to } 2.02) \\
(21: 15.92)\end{array}$ \\
\hline \multicolumn{4}{|l|}{$15-49$} \\
\hline WA & $\begin{array}{l}0.87(0.77 \text { to } 0.99) \\
(273: 313)\end{array}$ & $\begin{array}{l}0.87(0.75 \text { to } 1.00) \\
(197: 226)\end{array}$ & $\begin{array}{l}0.86(0.69 \text { to } 1.1) \\
(76: 87)\end{array}$ \\
\hline Scotland & $\begin{array}{l}1.21(1.12 \text { to } 1.31) \\
(617: 509.16)\end{array}$ & $\begin{array}{l}1.04(0.94 \text { to } 1.16) \\
(345: 331.68)\end{array}$ & $\begin{array}{l}1.53(1.36 \text { to } 1.73) \\
(272: 177.48)\end{array}$ \\
\hline \multicolumn{4}{|l|}{$\geq 50$} \\
\hline WA & $\begin{array}{l}1.02(0.93 \text { to } 1.12) \\
(456: 446)\end{array}$ & $\begin{array}{l}0.91(0.82 \text { to } 1.02) \\
(298: 326)\end{array}$ & $\begin{array}{l}1.32(1.13 \text { to } 1.54) \\
(158: 120)\end{array}$ \\
\hline Scotland & $\begin{array}{l}1.05(1.00 \text { to } 1.11) \\
(1602: 1523)\end{array}$ & $\begin{array}{l}0.94(0.88 \text { to } 1.00) \\
(884: 943.75)\end{array}$ & $\begin{array}{l}1.23(1.15 \text { to } 1.33) \\
(718: 579.25)\end{array}$ \\
\hline
\end{tabular}

analyses to explore the patient (including lifestyle factors such as smoking and alcohol) and injury factors associated with the observed cancer risk.

\section{Findings}

Analysis of the ISD Scotland data confirmed the results of our previous study: a statistically significant increase in total (all sites) cancer risk for female burn survivors with males experiencing no difference. The site-specific analyses clearly showed statistically significant increases in the number of observed cancers for combined gender in the Western Australia and Scottish data for the buccal cavity, larynx, liver, respiratory tract and oesophagus. There was also a general trend for increased cancer risk for a number of selected types of cancers for females and statistically significant increases in female genital cancers. Sub group analyses, defined crudely by reproductive age, did not elucidate any clear patterns of influence of oestrogen on cancer incidence, with female burn survivors in Scotland showing an increased risk across all age groups. For female burn survivors in WA, an increased risk for total (all sites) cancer was found for those younger than 15 (prepubescent) and 50 years and older (postmenopausal). The lack of gender difference for the subcohort of burn patients in Scotland hospitalised during 1983-1988 for total (all sites) cancer risk is difficult to explain. Possible reasons may include that females sustained less severe $(<20 \%$ TBSA) burns during this period; had less comorbidities and/or had better lifestyle factors than females hospitalised for burns during the remainder of the study period.

The site-specific analyses showed that while statistically significant increases in female genital cancers were found, there was also a general trend among female burn patients for excesses across a number of sitespecific cancers examined, although these excesses did not always reach statistical significance, possibly due to small numbers. Statistically significant increases in the number of observed cancers for combined gender were found in the Western Australia and Scottish data for the buccal cavity, larynx, liver, respiratory tract and oesophagus. These results are similar to those found in a Danish study $^{13}$ and may be related to tobacco or alcohol use among this patient population. However, it would be expected that inhalation injury may also increase the cancer risk of the upper and lower respiratory tract, and in the case of the diagnosis of hepatocellular cancer in a young male (12 years of age) burn patient in Western Australia $^{10}$ tobacco or alcohol use would be most unlikely attributable agents. Interestingly, the results of no increase in skin melanoma risk after burn injury in this study support findings of other population-based studies. $^{12} 13$

An alternative explanation for this increased incidence in cancer postburn may lie in the significant impact a burn injury has on the immune system, or the sustained oxidative and metabolic stress that are integral to the injury response. While burn injury predominantly affects the skin, it has been shown to cause a significant depression of humoral and cell-mediated immunity, 2627 sustained elevated levels of oxidative stress $^{28} \quad 29$ and prolonged elevation of hypermetabolic and stress hormone levels. $^{30} 31$ These effects have been demonstrated to persist for up to 3 years postinjury and can lead to long-term systemic impacts on other organs of the body. ${ }^{1}{ }^{32-36}$ Severe burn injury has been demonstrated to induce endoplasmic reticulum (ER) stress, in 
particular, in the liver. ${ }^{37}$ ER stress is a stress-response that initially facilitates cell survival but can switch to a proapoptotic signal with prolonged stress. ${ }^{37} 38$ However, it has also been shown that the ER stress response can become maladaptive, facilitating adaptation to hypoxic environments and promoting tumour growth. ${ }^{38} 39$ It is plausible that the array of host responses combined with the impact of the injury, therefore, creates an environment of increased susceptibility to cancer.

In addition to the observed increase in some of the selected site-specific cancers, the data support evidence for a gender dimorphism (a systematic difference between individuals of different sex in the same species) in response to burn injury. After burn injury, gender has been shown to be an important factor with respect to poorer outcomes for mortality ${ }^{40-43}$ and improved prognosis for multiple organ dysfunction syndrome, ${ }^{44}$ and sepsis, ${ }^{45}$ for females compared with males. Similar gender-based differences have also been reported in animal studies of burn injury. ${ }^{46-50}$

The impact of gender with respect to outcomes after burn injury is largely thought to stem from well-established differences in immune biology. There is a substantial volume of published literature to support a gender dimorphism in the immune response $\mathrm{e}^{51-54}$ and sepsis ${ }^{45}$ following injury that have impacts on health and mortality. ${ }^{41}{ }^{42}$ The majority of these studies support a more efficient and effective innate and adaptive immune responses in females, leading to a rapid clearance of infectious organisms driven by tissue resident cell populations. ${ }^{55}$ This 'advantageous' response reduces the risk of infection in females compared with males ${ }^{556}$ but leads to elevated risk of autoimmune disease. ${ }^{57}$ This dimorphism was thought to arise largely due to the impact of oestrogen on immune function. ${ }^{58}$ However, recent papers have demonstrated that these differences are not completely ablated by ovariectomy (in animal models) ${ }^{55}$ and others have shown that oestrogen can be deleterious to the immune response.$^{60}$ This suggests a role of other mediators, most likely expressed on the $\mathrm{X}$ chromosome, in the maintenance of the differential immune response. ${ }^{61} 62$ The evidence for gender differences in the immune response, to thermal and other trauma, and its impact on outcomes is substantial. Here, the evidence of an increased cancer incidence in selected types of cancer after burn injury, with a greater effect in females, suggests the systemic immune response to burn injury may be a mediator of cancer susceptibility.

\section{CONCLUSION}

Using population-based linked data of all burn patients in Western Australia and Scotland, consistent trends were found in excesses in cancer notifications for a range of selected site-specific cancers with an elevated and more widespread increase in female burn patients. Overall, however, the increased cancer risk affected a small proportion of the respective burn patient cohorts. More research is required to understand the underlying mechanism(s) that may link burn injury to an increased risk of some cancers and why this is elevated in females, which may in turn enable identification of possible sites for intervention.

Author affiliations

${ }^{1}$ Burn Injury Research Unit, School of Surgery, University of Western Australia, Crawley, Western Australia, Australia

${ }^{2}$ Population Health Research Network, Centre for Data Linkage, Curtin University, Perth, Western Australia, Australia

${ }^{3}$ Burns Service of Western Australia, Royal Perth Hospital and Princess

Margaret Hospital, Perth, Western Australia, Australia

${ }^{4}$ Fiona Wood Foundation, Crawley, Western Australia, Australia

Acknowledgements The authors would like to thank the staff of the Health Information Linkage Branch for access to the Western Australian Data Linkage System and Scottish Record Linkage team for their assistance in obtaining the data and providing advice on aspects of coding. Furthermore, the authors would like to thank the WA Health Data Custodians for access to the core health datasets and the Western Australian Department of Health and Information Service Division (ISD) Scotland for their assistance and advice.

Contributors JMD and JB participated in planning, conduct and reporting. JB, MWF, SR and FMW participated in reporting. JMD and JB are the guarantors.

Funding Project data costs were supported by an Australian National Health and Medical Research Council (533502) research grant and a Raine Medical Research Foundation Priming grant (12/2013). JMD, Senior Research Fellowship, is supported by Woodside corporate sponsorship via the Fiona Wood Foundation.

\section{Competing interests None.}

Ethics approval Department of Health Western Australia Human Research Ethics Committee; National Health Service (NHS) National Services Scotland Privacy Advisory Committee; University of Western Australia Human Research Ethics Committee.

Provenance and peer review Not commissioned; externally peer reviewed.

Data sharing statement No additional data are available.

Open Access This is an Open Access article distributed in accordance with the Creative Commons Attribution Non Commercial (CC BY-NC 3.0) license, which permits others to distribute, remix, adapt, build upon this work noncommercially, and license their derivative works on different terms, provided the original work is properly cited and the use is non-commercial. See: http:// creativecommons.org/licenses/by-nc/3.0/

\section{REFERENCES}

1. Anderson JR, Zorbas JS, Phillips JK, et al. Systemic decreases in cutaneous innervation after burn injury. J Investe Dermatol 2010;130:1948-51.

2. Jeschke MG, Gauglitz GG, Kulp GA, et al. Long-term persistance of the pathophysiologic response to severe burn injury. PLOS ONE 2011;6:e21245.

3. Rea S, Giles NL, Webb S, et al. Bone marrow-derived cells in the healing burn wound-more than just inflammation. Burns 2009;35:356-64.

4. Deveci M, Sengezer M, Bozkurt M, et al. Comparison of lymphocyte populations in cutaneous and electrical burn patients: a clinical study. Burns 2000;26:229-32.

5. Heideman $M$, Bengtsson $A$. The immunologic response to thermal injury. World J Surg 1992;16:53-6.

6. McGill SN, Cartotto RC. Herpes simplex virus infection in a paediatric burn patient: case report and review. Burns 2000;26:194-9.

7. O'Sullivan ST, O'Connor TP. Immunosuppression following thermal injury: the pathogenesis of immunodysfunction. Br J Plastic Surg 1997;50:615-23.

8. Sjoberg T, Mzezewa S, Jonsson $\mathrm{K}$, et al. Immune response in burn patients in relation to HIV infection and sepsis. Burns 2004;30:670-4. 
9. Jeschke MG, Barrow RE, Herndon DN. Extended hypermetabolic response of the liver in severely burned pediatric patients. Arch Surg 2004;139:641-7.

10. Harper A, Rea S, Wood F. Hepatocellular carcinoma in a young survivor of major burns. Burns 2008;34:572-4.

11. Duke J, Rea S, Semmens J, et al. Burn injury and cancer risk: a state-wide longitudinal study. Burns 2011;38:340-7.

12. Lindelof B, Krynitz B, Granath F, et al. Burn injuries and skin cancer: a population-based cohort study. Acta Dermato-Venereol 2008;88:20-2.

13. Mellemkjaer L, Holmich LR, Gridley G, et al. Risks for skin and other cancers up to 25 years after burn injuries. Epidemiology 2006;17:668-73.

14. Holman CDJ, Bass AJ, Rouse IL, et al. Population-based linkage of health records in Western Australia: development of a health service research linked database. Aust N Z J Public Health 1999; 23:453-9.

15. Kendrick S, Clarke J. The Scottish Record Linkage System. Health Bull 1993;51:72-9.

16. Duke J, Wood F, Semmens J, et al. A 26-year population-based study of burn injury hospital admissions in Western Australia. $J$ Burn Care Res 2011;32:379-86.

17. Threlfall T, Thompson JR. Cancer incidence and mortality in Western Australia, 2008. Statistical Series Number 87. Perth: Department of Health, Western Australia, 2010.

18. ISD Scotland. ISD Scotland, better information, better decisions, better health, http://www.isdscotland.org (accessed 12 Aug 2013).

19. Brewster $\mathrm{DH}$, Stockton $\mathrm{D}$, Harvey J, et al. Reliability of cancer registration data in Scotland, 1997. Eur J Cancer 2002;38:414-17.

20. Brewster DH, Stockton DL. Ascertainment of breast cancer by the Scottish Cancer Registry: an assessment based on comparison with five independent breast cancer trials databases. Breast 2008:17:104-6.

21. Gordis L. Epidemiology, 2nd edn. Philadelphia: W.B. Saunders Company, 2000.

22. Verkasalo PK, Pukkala E, Kaprio J, et al. Magnetic fields of high voltage power lines and risk of cancer in Finnish adults: nationwide cohort study. BMJ 1996;313:1047-51.

23. Bailar J III, Ederer F. Significance factors for the ratio of a poisson variable to its expectation. Biometrics 1964;20:639-43.

24. ISD Scotland. Assessmnet of SMR01 Data 2010-2011 Scotland Report May 2012. Edinburgh: NHS National Services Scotland, 2012.

25. Department of Health Western Australia. Clinical information audit program - hospital activity report. Operational Directive OD 0201/09. Perth Department of Health WA, 2009.

26. Horgan PG, Mannick JA, Dubravec DB, et al. Effect of low dose recombinant interleukin 2 plus indomethacin on mortality after sepsis in a murine burn model. Br J Surg 1990;77:401-4.

27. Schmand JF, Ayala A, Chaudry IH. Effects of trauma, duration of hypotension, and resuscitation regimen on cellular immunity after hemorrhagic shock. Crit Care Med 1994;22:1076-83.

28. Liu DM, Sun BW, Sun ZW, et al. Suppression of inflammatory cytokine production and oxidative stress by CO-releasing molecules-liberated $\mathrm{CO}$ in the small intestine of thermally-injured mice. Acta Pharmacol Sin 2008;29:838-46.

29. Shupp JW, Nasabzadeh TJ, Rosenthal DS, et al. A review of the local pathophysiologic bases of burn wound progression. J Burn Care Res 2010;31:849-73.

30. Atiyeh BS, Gunn SWA, Dibo SA. Metabolic implications of severe burn injuries and their management: a systematic review of the literature. World J Surg 2008;32:1857-69.

31. Williams FN, Herndon DN, Jeschke MG. The hypermetabolic response to burn injury and interventions to modify this response. Clin Plastic Surg 2009;36:583-96.

32. Ananthakrishnan P, Cohen DB, Xu DZ, et al. Sex hormones modulate distant organ injury in both a trauma/hemorrhagic shock model and a burn model. Surgery 2005;137:56-65.

33. Dreschsler S, Weixelbaumer K, Raeven P, et al. Relationship between age/gender-induced survival changes and the magnitude of inflammatory activation and organ dysfunction in post-traumatic sepsis. PLoS ONE 2012;7:e5147.

34. Borue X, Lee S, Grove J, et al. Bone marrow-derived cells contribute to epithelial engraftment during wound healing. Am J Pathol 2004; 165:1767-72.

35. Fan $\mathrm{Q}$, Yee $\mathrm{CL}$, Ohyama $\mathrm{M}$, et al. Bone marrow-derived keratinocytes are not detected in normal skin and only rarely detected in wounded skin in two different murine models. Exp Hematol 2006;34:672-9.
36. Harris RG, Herzog EL, Bruscia EM, et al. Lack of a fusion requirement for development of bone marrow-derived epithelia. Science 2004;305:90-3.

37. Jeschke MG, Finnerty CC, Herndon DN, et al. Severe injury is associated with insulin resistance, endoplasmic reticulum stress response, and unfolded protein response. Ann Surg 2012;255:370-8.

38. Verfaillie T, Garg AD, Agostinis P. Targeting ER stress induced apoptosis and inflammation in cancer. Cancer Lett 2013;332:249-64.

39. Wang $\mathrm{S}$, Kaufman RJ. The impact of the unfolded protein response on human disease. J Cell Biol 2012;197:857-67.

40. George RL, McGwin G Jr, Schwacha MG, et al. The association between sex and mortality among burn patients as modified by age. J Burn Care Rehabil 2005;26:416-21.

41. Kerby JD, McGwin G Jr, George RL, et al. Sex differences in mortality after burn injury: results of analysis of the National Burn Repository of the American Burn Association. J Burn Care Res 2006;27:452-6.

42. McGwin G Jr, George RL, Cross JM, et al. Gender differences in mortality following burn injury. Shock 2002;18:311-15.

43. O'Keefe GE, Hunt JL, Purdue GF. An evaluation of risk factors for mortality after burn trauma and the identification of gender-dependent differences in outcomes. J Am Coll Surg 2001;192:153-60

44. Frink M, Pape $\mathrm{H}-\mathrm{C}$, van Griensven $\mathrm{M}$, et al. Influence of sex and age on mods and cytokines after multiple injuries. Shock 2007; 27:151-6.

45. Schroder J, Kahlke V, Book M, et al. Gender differences in sepsis: genetically determined? Shock 2000;14:307-10; discussion 10-3.

46. Gregory MS, Duffner LA, Faunce DE, et al. Estrogen mediates the sex difference in post-burn immunosuppression. $J$ Endocrinol 2000;164:129-38.

47. Gregory MS, Faunce DE, Duffner LA, et al. Gender difference in cell-mediated immunity after thermal injury is mediated, in part, by elevated levels of interleukin-6. J Leukoc Biol 2000;67:319-26.

48. Kahlke V, Angele MK, Ayala A, et al. Immune dysfunction following trauma-haemorrhage: influence of gender and age. Cytokine 2000;12:69-77.

49. Kahlke V, Angele MK, Schwacha MG, et al. Reversal of sexual dimorphism in splenic T lymphocyte responses after trauma-hemorrhage with aging. Am J Physiol Cell Physiol 2000;278:C509-16.

50. Plackett TP, Gamelli RL, Kovacs EJ. Gender-based differences in cytokine production after burn injury: a role of interleukin-6. J Am Coll Surg 2010;210:73-8.

51. Croce MA, Fabian TC, Malhotra AK, et al. Does gender difference influence outcome? J Trauma Injury Infect Crit Care 2002:53:889-94.

52. Horton JW, White DJ, Maass DL. Gender-related differences in myocardial inflammatory and contractile responses to major burn trauma. Am J Physiol Heart Circ Physiol 2004;286:H202-13.

53. Mace JE, Park MS, Mora AG, et al. Differential expression of the immunoinflammatory response in trauma patients: burn vs. non-burn. Burns 2012;38:599-606.

54. Verthelyi D. Sex hormones as immunomodulators in health and disease. Int Immunopharmacol 2001;1:983-93.

55. Scotland RS, Stables MJ, Madalli S, et al. Sex differences in resident immune cell phenotype underlie more efficient acute inflammatory responses in female mice. Blood 2011;118:5918-27.

56. Sperry JL, Nathens AB, Frankel HL, et al. Characterization of the gender dimorphism after injury and hemorrhagic shock: are hormonal differences responsible? Crit Care Med 2008;36:1838-45.

57. Ozcelik T. X chromosome inactivation and female predisposition to autoimmunity. Clin Rev Allergy Immunol 2008;34:348-51.

58. Nicol T, Vernon-Roberts B, Quantock DC. Effect of orchidectomy and ovariectomy on survival against lethal infections in mice. Nature 1966:211:1091-2

59. Paavonen T. Hormonal regulation of immune responses. Ann Med 1994:26:255-8.

60. Rettew JA, Huet YM, Marriott I. Estrogens augment cell surface TLR4 expression on murine macrophages and regulate sepsis susceptibility in vivo. Endocrinology 2009;150:3877-84.

61. Libert C, Dejager L, Pinheiro I. The X chromosome in immune functions: when a chromosome makes the difference. Nat Rev Immunol 2010;10:594-604.

62. Pinheiro I, Dejager L, Libert C. X-chromosome-located microRNAs in immunity: might they explain male/female differences? The $X$ chromosome-genomic context may affect X-located miRNAs and downstream signaling, thereby contributing to the enhanced immune response of females. Bioessays 2011;33:791-802. 